\section{Renewable Energy Transition as an Instrument pf Foreign Policy: An Overview of Selected Issues}

\author{
Maciej Bukowski \\ Jagiellonian University, Institute of Political Science and International Relations, Poland
}

\begin{abstract}
The accelerating process of transitioning to renewable energy sources (RES), mandated by the global efforts to address climate change, represents the most far-reaching and structured energy transition in human history. At the same time, the relative conviction among carbon-intensive countries that future economic growth will only be possible in a decarbonised world promotes and rewards efforts to achieve decarbonisation through those technologies and know-how which governments themselves possess and are able to export. As a result, the community of interest in combating climate change requires taking into account divergent geopolitical interests stemming from the pursuit of what nominally is the same goal. The realization of this pursuit sees an increased instrumentalization of RES, resulting from competition for proliferation of certain technologies and exclusion of others, as well as from the growing rivalry to secure supply chains of critical minerals needed to manufacture RES infrastructure. This multifaceted phenomenon calls for greater scrutiny. The paper will attempt to identify some of the key issues and offer tentative analysis.
\end{abstract}

Keywords: RES, supply chains, critical minerals, geopolitics 